\section{Association between ankylosing spondylitis and venous thromboembolism}

Ankylosing spondylitis is a type of arthritis that commonly affects the joints of the spine. The relationship between ankylosing spondylitis and other diseases has been extensively explored. ${ }^{12}$ Recently, a cohort study in Canada conducted by Aviña-Zubieta et al published in Annals of Rheumatic Diseases disclosed that people with ankylosing spondylitis were at higher risk of venous thromboembolism compared with people without ankylosing spondylitis (HR 1.53, 95\% CI 1.16 to 2.01). ${ }^{3}$ AviñaZubieta et al's study is well performed and is informative to the researchers. Some of my views are shared with the readers as follows. First, the overall incidence of venous thromboembolism was 2.03-fold higher in people with ankylosing spondylitis than in those people without ankylosing spondylitis in Aviña-Zubieta et al's study (1.56 vs 0.77 per 1000 person-years). ${ }^{3}$ The attributable risk associated with ankylosing spondylitis was 0.79 per 1000 person-years; that is, removal of ankylosing spondylitis can diminish approximately eight cases of venous thromboembolism per 10000 person-years of follow-up. Second, another cohort study in the Republic of Korea disclosed that the overall incidence of new onset of atrial fibrillation was 1.54-fold higher in people with ankylosing spondylitis than in those without ankylosing spondylitis (2.32 vs 1.51 per 1000 person-years). ${ }^{4}$ The attributable risk associated with ankylosing spondylitis was 0.81 per 1000 person-years; that is, removal of ankylosing spondylitis can diminish approximately eight cases of new onset of atrial fibrillation per 10000 person-years of follow-up. According to the above measurement, ankylosing spondylitis seems to have a similar impact on the risks of venous thromboembolism and new onset of atrial fibrillation. Third, the evidence disclosed that people with ankylosing spondylitis who underwent tumour necrosis factor inhibitor therapy had a higher risk of new onset of atrial fibrillation (HR 1.60, 95\% CI 1.02 to 2.39 ), ${ }^{4}$ but Aviña-Zubieta et al's study did not disclose such data. I agree with Aviña-Zubieta et al's comments that future investigation is needed to clarify the effects of ankylosing spondylitis treatment on the risk of venous thromboembolism. Fourth, ankylosing spondylitis cannot be prevented and is less likely to be eradicated. Currently, the guidelines for stroke prevention in people with atrial fibrillation have been established. ${ }^{5}$ In addition, it is important to recognise people who have risk factors for venous thromboembolism, including those having cancer, major surgery, major trauma-like fractures and long-term immobilisation. ${ }^{6}$ Clinicians who participate in the long-time care of people with ankylosing spondylitis should take into consideration the above risk factors when considering the risk of venous thromboembolism. If necessary, pharmacological prophylaxis for venous thromboembolism should be initiated in these highrisk people.

Shih-Wei Lai ${ }^{1,2}$

${ }^{1}$ Department of Public Health, College of Public Health and School of Medicine, College of Medicine, China Medical University, Taichung, Taiwan

${ }^{2}$ Department of Family Medicine, China Medical University Hospital, Taichung, Taiwan

Correspondence to Dr Shih-Wei Lai, Department of Family Medicine, China Medical University Hospital, Taichung 404, Taiwan; wei@mail.cmuh.org.tw

Correction notice This article has been corrected since it published Online First. The first affiliation has been updated.

Handling editor Josef S Smolen

Contributors S-WL contributed to the conception of the article, initiated the draft of the article and approved the final draft submitted.

Funding The authors have not declared a specific grant for this research from any funding agency in the public, commercial or not-for-profit sectors.

Competing interests None declared.

Patient consent for publication Not necessary

Provenance and peer review Not commissioned; internally peer reviewed.

(C) Author(s) (or their employer(s)) 2019. No commercial re-use. See rights and permissions. Published by BMJ.

\section{Check for updates}

To cite Lai S-W. Ann Rheum Dis Epub ahead of print: [please include Day Month Year]. doi:10.1136/annrheumdis-2019-215854

Received 7 June 2019

Accepted 8 June 2019

Ann Rheum Dis 2019;0:1. doi:10.1136/annrheumdis-2019-215854

ORCID iD

Shih-Wei Lai http://orcid.org/0000-0002-7420-1572

\section{REFERENCES}

1 Chen $\mathrm{H}-\mathrm{H}$, Yeh S-Y, Chen $\mathrm{H}-\mathrm{Y}$, et al. Ankylosing spondylitis and other inflammatory spondyloarthritis increase the risk of developing type 2 diabetes in an Asian population. Rheumatol Int 2014;34:265-70.

2 Sun L-M, Muo C-H, Liang J-A, et al. Increased risk of cancer for patients with ankylosing spondylitis: a nationwide population-based retrospective cohort study. Scand J Rheumatol 2014;43:301-6.

3 Aviña-Zubieta JA, Chan J, De Vera M, et al. Risk of venous thromboembolism in ankylosing spondylitis: a general population-based study. Ann Rheum Dis 2019;78:480-5.

4 Moon I, Choi E-K, Jung J-H, et al. Ankylosing spondylitis: A novel risk factor for atrial fibrillation - A nationwide population-based study. Int J Cardiol 2019;275:77-82.

5 Proietti M, Lane DA, Boriani G, et al. Stroke prevention, evaluation of bleeding risk, and anticoagulant treatment management in atrial fibrillation contemporary international guidelines. Can J Cardiol 2019;35:619-33.

6 Goldhaber SZ. Risk factors for venous thromboembolism. J Am Coll Cardiol 2010;56:1-7. 